\title{
EDITORIAL
}

\section{CHANGING INDICATIONS FOR PENETRATING KERATOPLASTY}

The world of ophthalmology was saddened by the untimely death of Thomas Aquinas Casey. His contribution to corneal surgery was immense and his pre-eminent place there is unlikely to be filled. Evidence of this is presented in this issue in the paper. 'Changing indications for penetrating keratoplasty, 1971-1990'. ' Over 3500 corneal transplants were performed over a 20 year period - a prodigious amount of surgery for a single, consultant-led team. That so many patients and fellow ophthalmologists trusted him is, itself, a tribute to the man.

The paper is, however, more than a tribute to Mr Casey. Few published series can approach it in size. The workload described is idiosyncratic and certainly different from previously published series either in this country or in the United States of America. Morris and Bates ${ }^{2}$ reported that keratoconus was the commonest indication for penetrating keratoplasty at Moorfields Eye Hospital during a 3 year period whereas the UKTSS reported in 1992 (personal communication) that aphakic and pseudophakic bullous keratopathy was the commonest indication amongst its users. At approximately $22 \%$, this is still far below the $50 \%$ or greater quoted in many American series ${ }^{3-5}$ for secondary bullous keratopathy, which has for many years been the major indication for penetrating keratoplasty in that country. Data from other countries, particularly in Europe, are sparse. Morris and Bates ${ }^{2}$ were able to indicate that there was a decline in the proportion of cases operated on for herpes simplex keratitis by quoting Ainslie's small series from 1974: ${ }^{6}$ Sharif and Casey ${ }^{1}$ confirm this impression. Whether this is due to improved management or our better understanding of the prognosis of keratoplasty for herpes simplex is a moot point. Although all the British series differ, it is quite clear that the pattern of indications for penetrating keratoplasty is markedly different from that in the United States.

Sharif and Casey's ${ }^{1}$ unusually high proportion of regrafts in a tertiary referral centre gives an insight into referral patterns for corneal graft surgery and suggests that many surgeons are happy to undertake first grafts but not regrafts. This may not be entirely logical since MacEwan et al. ${ }^{7}$ \& Kirkness et al. ${ }^{8}$ have clearly demonstrated the reduced graft survival in regrafts and that the best chance of graft survival is in first grafts.

Until the national patterns of corneal transplantation are clear we are not in a position to analyse accurately the changing trends of indications for keratoplasty nor successes thereafter. The UKTSS collects data on grafts for which it supplies donors but there is no national registry for corneal transplantation. Such a register would greatly increase our understanding of the role of keratoplasty in restoring sight nationwide.

C. M. KIRKNESS

\section{References}

1. Sharif W, Casey TA. Changing indications for penetrating keratoplasty, 1971-1990. Eye 1993;7:485-8.

2. Morris RJ, Bates AK. Changing indications for keratoplasty. Eye 1989;3:455-9.

3. Smith RE, McDonald HR, Nesburn AB, Minckler DS. Penetrating keratoplasty: changing indications, 1974-1978. Arch Ophthalmol 1980;98:1226-9.

4. Robin JB, Gindi JJ, Koh K, Schanzlin DJ, Rao NA, York KK, et al. An update of the indications for penetrating keratoplasty 1979-83. Arch Ophthalmol 1986;104:87-9.

5. Brady SF, Rapuans CJ, Arentsen JJ, Cohen EJ, Laibson PR. Clinical indications for and procedures associated with penetrating keratoplasty 1983-88. Am J Ophthalmol 1989;108:118-22.

6. Ainslie D. Corneal grafting: a comparison between then and now. Trans Ophthalmic Soc UK 1974;94:137-43.

7. MacEwan CJ, Khan ZU, Anderson A, MacEwan CG. Corneal regraft: indications and outcome. Ophthalmic Surg 1988;19:706-12.

8. Kirkness CM, Ezra E, Rice NSC, Steele ADMcG. The success and survival of repeat corneal grafts. Eye 1990;4:58-64. 